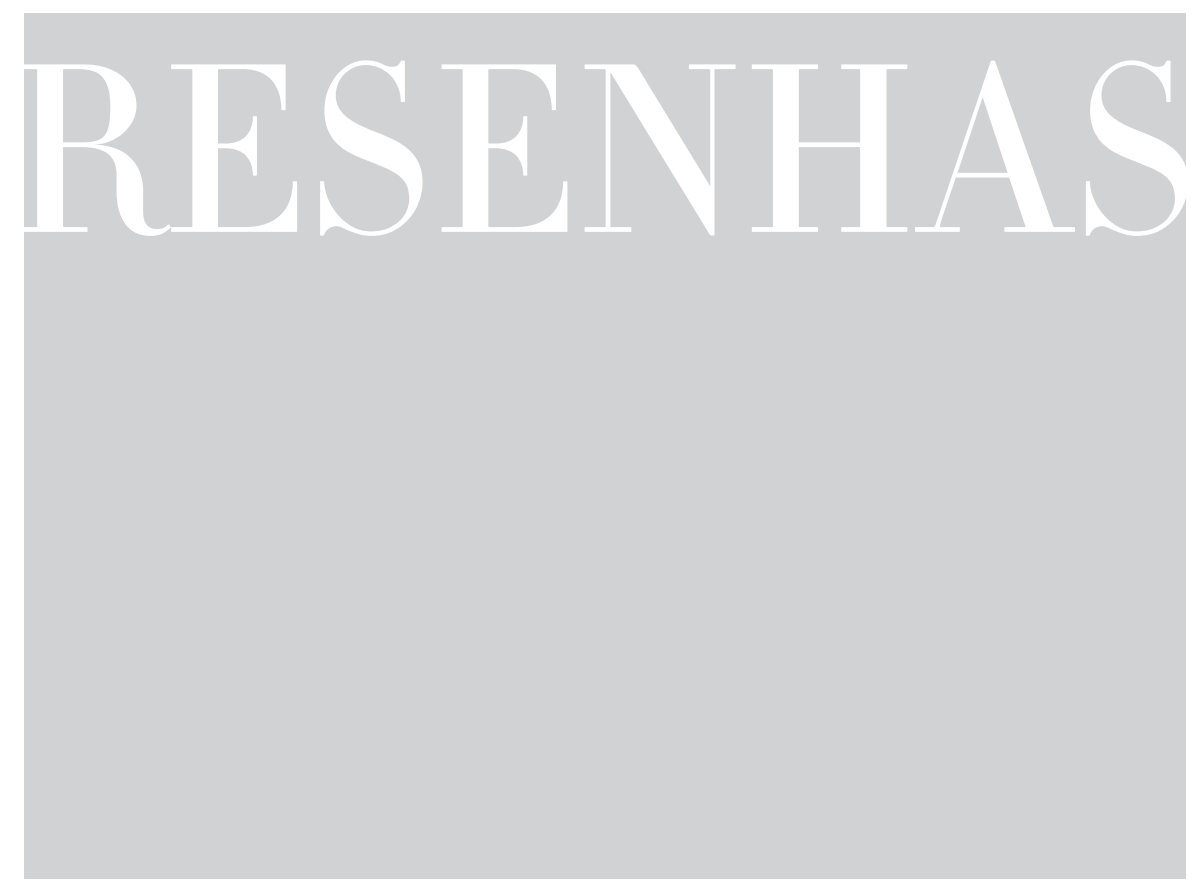

\title{
POR UMA ANTROPOLOGIA DA INFÂNCIA: PESQUISANDO O RECREIO
}

DELALANDE, Julie. La cour de la récréation. Pour une anthropologie de l'enfance. Rennes: Presses Universitaires de Rennes, 2001. 278 p

Embora La cour de la récréation, da antropóloga Julie Delalande, tenha sido publicado na França em 2001, uma resenha em 2014 se justifica porque o debate apresentado pela autora permaneceu inédito no Brasil até recentemente, quando a comunidade acadêmica despertou o interesse por estudos da antropologia da infância.

O livro é resultado da tese na qual Delalande assume como ponto de partida as seguintes questões: o que produzem as crianças entre elas, sem a participação dos adultos? O que dizem quando estão entre pares? Como num pátio de recreação estruturam suas relações? O que jogam e de onde vêm seus conhecimentos dos jogos? Situado no campo da antropologia social e etnografia, o estudo focaliza as crianças como informantes privilegiados. Mostra a maneira como adquirem regras e valores da sociedade ao estarem entre seus pares, considerando-as como atores sociais - do presente - e não como seres futuros - um vir a ser. Mais do que investigar as práticas pedagógicas que cercam o jogo e seu papel na socialização infantil (mesmo que a pesquisa responda a essas questões), o objetivo é penetrar no pátio das escolas e compreender seu funcionamento enquanto uma microssociedade. 
O livro é organizado em duas partes. A primeira, "Poser son regard sur l'enfance" [Lançar seu olhar sobre a infância], trata do conceito de infância; da infância como campo de pesquisa; do pátio de recreio como espaço de observação; da metodologia; e do jogo. A segunda, "La cour comme micro-société" [O pátio como microssociedade], apresenta os elementos do campo que dão suporte à ideia de que a cultura infantil, desenvolvida na sociedade do pátio, no contexto escolar, não é em nada separada da sociedade global. A cultura infantil forma, ao contrário, uma unidade social e cultural vivida pelas crianças.

A pesquisa foi realizada entre os anos de 1992 e 1997 em quatro instituições: três no oeste da França (uma delas rural) e uma na região parisiense. Os sujeitos foram crianças do maternal e da escola elementar de diferentes classes sociais.

Através de uma escrita clara e consistente, a autora nos conduz a cenas vividas pelas crianças, convidando-nos a olhar a pesquisa com crianças tendo a ética como foco e a infância como um produto da e para a cultura. A descrição densa é uma das características do trabalho. Embora tenha uma base metodológica extremamente detalhada, o trabalho de campo e a análise dos dados são o ponto central do texto. Delalande apresenta sua questão de forma tão envolvente que, caso o leitor considere o recreio como um momento barulhento e pouco produtivo, logo passa a reconhecê-lo como espaço de perpetuação e produção da cultura infantil. O pátio é um local de socialização das crianças entre elas, numa relação de autonomia e poder. É nesse espaço que se constituem como grupo, criando laços de amizade através da distribuição dos papéis no jogo e do lugar que cada um ocupa nesse contexto. Jogando, apropriam-se de certas regras e valores dos adultos sobre os quais fundam seus conceitos de justiça e solidariedade.

Delalande dedica especial atenção à análise da brincadeira de pai e mãe. Nessa prática encontram-se os modelos das relações familiares vividas ou observadas pelas crianças. Estas brincam de mãe e pai pelo prazer de se incluírem em uma situação que os coloca como membros de uma cultura. Observando as crianças mais velhas do maternal, a autora percebe o orgulho de quem assume o papel do adulto, papel que se reserva aos líderes do grupo. Alimentado por elementos do cotidiano, pelo papel familiar e pelas regras da vida que as crianças conhecem, o jogo torna-se estereotipado. Dessa forma, os traços característicos variam pouco, mesmo em diferentes contextos. Encontra-se na encenação a autoridade paternal, o espírito lúdico das crianças e a dificuldade em tornar os dois compatíveis. Os jogos permitem pensar o mundo dos adultos e questionar coletivamente os mitos e tabus. Nessa dramatização, encontram-se relações de força, de autoridade, de cumplicidade e de conflito.

Feitas essas considerações, a antropóloga passa a discutir como o pátio pode ser compreendido como uma microssociedade. Para além de um espaço de desordem, sem lógica, o pátio é um local onde se pode 
identificar a organização das crianças em grupos. Ao optar por esse espaço de observação, Delalande pretende compreender como se formam os grupos de pares, como funcionam e em que medida estão ligados à situação de jogo. A constituição de pequenos grupos infantis - sem a interferência dos adultos - no espaço do pátio escolar permite o aprendizado de uma sociabilidade. As crianças aprendem "a se virar", umas com as outras, numa confrontação que as obriga a gerir as relações humanas, em uma igualdade de status que não existe numa relação entre crianças e adultos.

Para Delalande, quando as crianças brincam juntas durante dias seguidos, uma solidariedade ganha forma graças ao jogo. O jogo cria uma ligação de dependência entre os participantes que devem se aliar para jogar. Assim, é o jogo que liga as crianças, favorecendo seus relacionamentos.

A autora trabalha com duas categorias: o grupo e a solidariedade infantil. O grupo é uma categoria central na análise da vida recreativa. Observando grupos, destaca que alguns aparecem como amorosos e acolhedores, outros como arrogantes e audaciosos, outros competitivos. A outra categoria, a solidariedade infantil, é necessária para a prática do jogo. O desejo de jogar é o que aproxima as crianças; tornando esse objetivo comum, estabelecem elos de solidariedade. A brincadeira permite o nascimento de uma relação amigável, solidária. Para a realização do jogo, cada participante deve executar um papel específico, que só tem sentido no coletivo. O jogo coletivo só é possível através dessa forma de solidariedade que surge para estruturar, gerar interesse e definir regras.

Mergulhando no tema da solidariedade, Delalande considera que dar e trocar são provas de solidariedade por parte das crianças. Segundo os valores infantis, dar é um dos meios mais eficazes de ser aceito pelo grupo. Trocando ou dando, as crianças fazem aprendizagens de uma regra elementar de sociabilidade: dar permite entrar em um grupo de pares, e mesmo em um círculo de amigos; guardando, desvincula-se dos outros, condenando-se a brincar sozinho. É preciso valorizar a disposição à doação - a criança, ao oferecer para as demais qualquer coisa que faça parte da brincadeira, demonstra aos outros sua confiança e sua vontade de partilhar. A troca não é apenas um ritual de ser educado, mas pode ser vista como uma forma de fazer com que a sociedade seja coesa, parceira. A troca alimenta uma atitude cultural que privilegia a relação com o outro.

Jogar é a oportunidade de cada criança afirmar um lugar para si no grupo, de desvendar características suas e dos demais, de se fazer, por consequência, apreciar ou não, e, nesse sentido, construir uma reputação entre os pares. A instauração de relações agradáveis passa pelo estabelecimento de relações de poder. No que diz respeito a situações que podem ser consideradas como de inimizade, essas são a manifestação do interesse das crianças pelo outro. Cada criança deve encontrar nela mesma a resposta para uma situação de conflito, de modo que a relação com o outro não a reprima, sendo uma relação prazerosa de troca. 
Na escola maternal, a amizade se manifesta pela participação na atividade do outro. As crianças viram amigas brincando juntas, depois cultivam esse lugar tornando-se companheiras de jogo. Nesse grupo, primeiro se envolvem em uma brincadeira antes de descobrirem se possuem ou não afinidades. O movimento contrário ocorre quando elas crescem. No jogo, aproximam-se, mas as relações de amizade são estabelecidas de acordo com a afinidade entre elas. Mas, como nenhuma ligação é definitiva, encontram-se constantemente discursos como "eu sou seu amigo" ou "eu não sou mais seu amigo”. Esse é um exercício no qual as crianças definem o que caracteriza os atos e o papel de um amigo. A autora afirma que, no maternal, as crianças atrelam em seus discursos o fato de serem amigas ao fato de brincarem juntas. Com o tempo, essa justificativa muda, e elas reconhecem a amizade por aqueles que julgam que respeitam as regras de convivência coletiva.

Nas diferentes escolas foram encontradas características comuns na maneira de se fazer funcionar um grupo. Essas características estão relacionadas à forma como distribuem os papéis, como trocam objetos e materiais e mostram sua adesão ao jogo, imitando alguém.

Enveredando no cotidiano dos grupos, a pesquisadora se dedica à figura do líder. O líder tem um papel fundamental no jogo. Embora seja o responsável pela organização e por sua duração, em sua ausência as crianças criam outras formas de ligação para estruturar a relação entre elas. A figura do líder esteve presente em todos os grupos pesquisados. Sua maneira de proceder é semelhante nos diferentes contextos. À figura do líder cabe o papel de proteger e fazer justiça. Ele deve fazer reinar uma boa atmosfera evitando sobrecargas. Da parte das meninas, a gentileza, a doçura, a amabilidade e o sucesso escolar são algumas características do líder. Da parte dos meninos, os critérios se fundam na amizade, gentileza, vitalidade esportiva e força física.

Delalande conclui o estudo afirmando que os professores intervêm na ação da criança para ensinar em uma relação hierárquica. Entre pares, as crianças aprendem em condições de igualdade relativamente próximas daquelas que encontrarão quando crescerem. Dessa forma, socializam-se não somente adaptando-se, mas entrando no processo de apropriação, reinvenção e produção do social.

\section{ANELISE MONTEIRO DO NASCIMENTO \\ Doutora em Educação pela PUC-Rio; professora adjunta do Departamento de Educação e Sociedade da Universidade Federal Rural do Rio de Janeiro - UFRRJ anelise.ufrrj@yahoo.com.br}

\section{KARLA RIGHETTO RAMIREZ DE SOUZA}

Doutoranda em Educação pela Universidade Federal do Rio de Janeiro - UFRJ; professora do Colégio de Aplicação da UFRJ

karlarighetto@gmail.com 